\section{TUBERCULOSIS LATENTE: COBERTURA QUIMIOPROFILÁCTICA DE CONTACTOS INTRADOMICILIARIOS EN EL PERÚ}

\section{[LATENT TUBERCULOSIS: CHEMOPROPHYLACTIC COVERAGE OF HOUSEHOLD CONTACTS IN PERU]}

\author{
Julio Maquera-Afaray ${ }^{1}$
}

Sr. Editor. Con mucho interés he leído el artículo "Reactividad de la prueba de tuberculina en contactos intradomiciliarios de pacientes con tuberculosis en Huánuco, Perú", publicado por Dámaso et al. (1), y concuerdo con la mayoría de los puntos expuestos; no obstante, sus hallazgos me permiten comentar respecto a la vigente normativa para el control de la tuberculosis (TB) en el Perú (2), específicamente en su acápite de estudio de contactos y quimioprofilaxis.

En el Perú, la indicación quimioprofiláctica en contactos sin evidencia de enfermedad activa se ha limitado a los menores de 20 años de edad e infectados por el virus de inmunodeficiencia humana (VIH/SIDA) ${ }^{(2)}$. Sin embargo, diversa evidencia científica ha demostrado mayor riesgo de infección y enfermedad tuberculosa, en mayores de 19 años de edad, denotando la existencia de un grupo, a considerar, de contactos con infección latente no diagnosticada ni tratada ${ }^{(1,3)}$; además, debido que el mayor riesgo de infección y enfermedad de los contactos se produce durante los primeros meses, la intervención quimioprofiláctica debería hacerse lo antes posible y priorizando a los contactos intradomiciliarios (3). Ante este contexto surge la interrogante: ¿será acaso necesario ampliar la cobertura quimioprofiláctica antituberculosa en el Perú?

Según el Plan global para detener la TB 2006-2015, la Organización Mundial de la Salud (OMS) ha planteado como objetivo y esperanza, poder contar con una prueba diagnóstica para la TB latente que identifique su riesgo de activación y permita focalizar apropiadamente la quimioprofilaxis ${ }^{(4)}$. Mientras tanto, es necesario e importante desarrollar más estudios sobre el tema en el país, que nos permitan estructurar alternativas adecuadas.

Estudiante de Medicina, Facultad de Ciencias Médicas, Universidad Nacional Jorge Basadre Grohmann. Tacna, Perú.

Recibido: 02-05-10 Aprobado: 12-05-10
Finalmente, aunque la situación de TB en el Perú evidencia una tendencia decreciente, continúa reportando altas tasas de incidencia en América Latina; por eso, es incuestionable que un país de recursos limitados y con elevada carga de enfermedad priorice sus esfuerzos en el diagnóstico y tratamiento de personas con TB activa; sin embargo, para poder alcanzar estándares de control óptimos, es necesario ampliar e intensificar el marco de su estrategia, incluyendo, entre otros, a la investigación de los contactos intradomiciliarios, considerados de alta prioridad por su grado exposición a un caso de TB y cuya probabilidad de desarrollo de infección y enfermedad es mayor (4-6), constituyendo un nuevo foco de infección y concadenando el círculo de múltiples e interconectados factores que limitan mayores progresos en el control de la TB.

\section{Conflictos de interés}

El autor declara no tener conflictos de interés en la publicación de este artículo.

\section{REFERENCIAS BIBLIOGRÁFICAS}

1. Dámaso B, Díaz R, Menacho L, Loza C. Reactividad de la prueba de tuberculina en contactos intradomiciliarios de pacientes con tuberculosis en Huánuco, Perú. Rev Peru Med Exp Salud Publica. 2009; 26(4): 449-54.

2. Perú, Ministerio de Salud. Norma técnica de salud para el control de la tuberculosis. Lima: MINSA/DGSP; 2006.

3. Salinas C, Capelastegui A, Altube L, España PP, Díez $\mathbf{R}$, Oribe $\mathbf{M}$, et al. Incidencia longitudinal de la tuberculosis en una cohorte de contactos: factores asociados a la enfermedad. Arch Bronconeumol. 2007; 43(6): 317-23.

4. Stop TB Partnership, World Health Organization. Global plan to stop TB 2006 - 2015. Geneva: WHO; 2006.

5. National Tuberculosis Controllers Association; Centers for Disease Control and Prevention. Guidelines for the investigation of contacts of persons with infectious tuberculosis. Recommendations from the National Tuberculosis Controllers Association and CDC. MMWR Recomm Rep. 2005; 54(RR-15): 1-47.

6. Perú, Ministerio de Salud. Plan Estratégico multisectorial de la respuesta nacional a la tuberculosis en el Perú 20092018. Lima: MINSA; 2009.

Correspondencia: Julio Maquera-Afaray

Dirección: Urb. Vigil, calle San Camilo N. ${ }^{\circ}$ 560, Tacna, Perú.

Correo electrónico: vigo_ma@hotmail.com

La carta fue remitida a la Estrategia Sanitaria Nacional de Prevención y Control de la Tuberculosis del Ministerio de Salud, quienes elaboraron la siguiente respuesta. 